\title{
Evaluation of Feeding Dairy Cow with Whole Wheat Hay and Alfalfa
}

\author{
Tian Zhang1*, Deqing Zhang2², Jinxin Wang1, Qiuling Hou'1, Yun Wang1, Zhiyong Hu1, \\ Xueyan Lin ${ }^{1 \#, ~ Z h o n g h u a ~ W a n g 1 \# ~}$ \\ ${ }^{1}$ College of Animal Science, Shandong Agricultural University, Taian, China \\ ${ }^{2}$ Laboratory Department, Taian Central Hospital, Taian, China \\ Email: "xueyanlin2005@163.com, "zhwang@sdau.edu.cn
}

How to cite this paper: Zhang, T., Zhang, D.Q., Wang, J.X., Hou, Q.L., Wang, Y., Hu, Z.Y., Lin, X.Y. and Wang, Z.H. (2018) Evaluation of Feeding Dairy Cow with Whole Wheat Hay and Alfalfa. Advances in Bioscience and Biotechnology, 9, 409-422. https://doi.org/10.4236/abb.2018.99029

Received: July 24, 2018

Accepted: September 9, 2018

Published: September 12, 2018

Copyright $\odot 2018$ by authors and Scientific Research Publishing Inc. This work is licensed under the Creative Commons Attribution International License (CC BY 4.0).

http://creativecommons.org/licenses/by/4.0/

\begin{abstract}
The preliminary results of this laboratory (unpublished) indicate that the nutritional value of whole wheat hay (wheat hay, for short) is very high, and the milk stage is the best period of wheat hay harvest. In this study, we investigated the feeding effect and economic benefits using wheat hay instead of alfalfa diet for dairy cows under the condition of the same energy and crude protein levels. Three types of diets were used: alfalfa diet, wheat hay diet and alfalfa + wheat hay diet. The results showed that the dry matter digestibility of alfalfa diet and alfalfa + wheat hay diet did not differ significantly $(\mathrm{P}>0.1)$, but was significantly higher than that of wheat hay diet $(P<0.05)$. The wheat hay diet could produce more propionic acid and ammonia nitrogen $(\mathrm{P}<$ $0.05)$ in the rumen, and reduce the ratio of acetic/propionic and nitrogen utilization. There was no significant difference in milk production among the three diets $(\mathrm{P}>0.1)$. There was no significant difference in milk somatic cell count and body condition score among the three groups $(\mathrm{P}>0.1)$. The wheat hay diet could significantly increase milk protein and lactose $(P<0.01)$. The contents of interleukin- 6 in cows fed alfalfa diet and alfalfa + wheat diet were significantly higher than that in cows fed wheat hay diet $(P<0.05)$. There was no significant difference in interleukinm- 6 between in cows fed alfalfa diet and alfalfa + wheat $\operatorname{diet}(\mathrm{P}>0.05)$. The use of wheat hay to replace imported alfalfa in whole or in part could save feed costs. Full substitution of alfalfa with wheat hay could have a daily economic benefit of 13.74 yuan.
\end{abstract}

\section{Keywords}

Cow, Whole Wheat Hay, Alfalfa, Feeding Effect, Economic Benefit

\footnotetext{
${ }^{\star}$ This authors have equal contribution to this article.
} 


\section{Introduction}

Roughage is the material guarantee of herbivorous animal husbandry. In cow production, the proportion and the quality of roughage are important factors affecting the performance of dairy cows. A high yield of dairy cow must be supported by high quality roughage. Since the production of high-quality roughage is insufficient in China, its roughage supply mainly relies on imports [1]. This shortage is the major reason for the far lower level of average yield per cow in China than the world level. Although it is possible to alleviate the shortage of high quality roughage in China through importation, this greatly increases the feed cost of the domestic cattle industry. The shortage of high quality roughage has become a major problem of the animal husbandry in China, especially the dairy farming industry. Wheat is one of the most grown crops in the world and is widely cultivated in northern China. Whole wheat hay (wheat hay, for short) has a high level of digestible fiber and energy, can be used as high-quality feed for high-quality cow or beef cattle [2]. Wheat hay is widely used in dairy cattle feed in some areas of Israel, Turkey and the United States, because of its strong adaptability and high nutritional value. Wheat hay had a higher feed intake by beef calves than whole plant wheat silage, and the apparent digestibility of DM and NDF was also higher for whole wheat plant hay [3]. This laboratory preliminary study (unpublished) indicates that the nutritional value of wheat hay is high. Considering wheat quality, yield and local planting structure, the milk stage was found to be the best period of harvesting and tempering the wheat hay. If the potential of wheat hay as feed resources is fully realized, the crop is harvested appropriately and made into high quality hay for dairy cow feed; it is possible to alleviate the shortage of roughage production, providing new roughage resources. Using wheat hay can also improve the utilization efficiency of wheat straw and reduce the environmental and production problems caused by the unreasonable use of wheat straw. It is of great significance to use wheat hay as a dairy cattle feed. The aim of this study was to evaluate the effects and economic benefits of wheat hay instead of imported alfalfa for feeding lactating dairy cows.

\section{Materials and Methods}

\subsection{Test Animals}

Ninety-six Holstein lactating dairy cows were selected from Shandong Gaosu Dairy Farm, of which 48 cows were primipara and 48 were multipara. The milk yield was $29.9 \pm 7.2 \mathrm{~kg} /$ day and the number of lactation days was $70 \pm 27$ days.

Throughout the trial period, the cows were free to access feed and water, milked three times a day, at $6 \mathrm{am}, 1 \mathrm{pm}$ and $6 \mathrm{pm}$.

\subsection{Experimental Design}

Dairy cows were randomly assigned into three groups, 32 cows per group, based their delivery history. Each group was randomly assigned to a treatment. Group 
$\mathrm{X}$ was fed wheat hay diet. Group MX was fed wheat hay + alfalfa diet (Table 1), and group $\mathrm{M}$ was fed alfalfa diet. The entire trial period was 6 weeks, including 1 week of pre-feeding period and 5 weeks of sampling period.

\subsection{Test Diets}

The test diets are listed in Table 2.

The diet for the alfalfa group (group M) was the high-yielding milk cow formula used by the cattle farms of Shandong Gaosu Dairy Farm. Wheat hay was used to replace $100 \%$ and $50 \%$ alfalfa, respectively, in the diets for the wheat group (group X), and the wheat-alfalfa (group MX), on the basis of Group M diets. The concentrate composition was adjusted, so that the three groups of diets met the requirement for net energy and crude protein. The diet is agitated with total mixed rations (TMR) before feeding.

\subsection{Sample Collection and Determination}

During the trial, the amount of feed and the amount of residual diets were recorded every week.

During the trial period, milk samples were collected and the milk production

Table 1. Chemical composition of wheat hay and alfalfa.

\begin{tabular}{ccc}
\hline Chemical composition & Wheat hay & Alfalfa \\
\hline DM\% & 92.53 & 89.34 \\
CP (\%DM) & 10.03 & 19.23 \\
NDF (\%DM) & 63.55 & 48.92 \\
ADF (\%DM) & 23.90 & 38.28 \\
\hline
\end{tabular}

Table 2. Diet composition and material prices.

\begin{tabular}{ccccc}
\hline Material & $\mathrm{X}$ & $\mathrm{MX}$ & $\mathrm{M}$ & Price (yuan $/ \mathrm{kg})$ \\
\hline Alfalfa $(\mathrm{kg})$ & 0 & 3.0 & 6.0 & 2.73 \\
Wheat hay $(\mathrm{kg})$ & 6.0 & 3.0 & 0 & 1.50 \\
Corn silage (kg) & 14.0 & 14.0 & 14.0 & 0.50 \\
Corn (kg) & 0 & 0.40 & 0 & 1.80 \\
Soybean meal (kg) & 1.60 & 1.00 & 0 & 3.10 \\
Premix (kg) & 11.25 & 11.25 & 12.50 & 2.75 \\
Cottonseed (kg) & 1.50 & 1.50 & 1.5 & 2.91 \\
Concentrate:roughage & $55: 45$ & $55: 45$ & $55: 45$ & - \\
CP (\%) & 16.20 & 16.20 & 16.20 & - \\
NEl (Mcal/kgDM) & 1.68 & 1.68 & 1.68 & - \\
\hline
\end{tabular}

Note: Alfalfa was of high quality imported from USA (Qingdao Aimuson Trading Co.). The concentrate was manufactured by Shandong Meida Food and Agriculture Co., Ltd. Each $12.5 \mathrm{~kg}$ of concentrate contained $6 \mathrm{~kg}$ corn, $2 \mathrm{~kg}$ soybean meal, $2 \mathrm{~kg}$ corn grit, $1 \mathrm{~kg}$ puffed soybeans, $1 \mathrm{~kg}$ barley and $0.5 \mathrm{~kg}$ premix. The feed price is the market price at the time of the trial. 
was recorded. The milk composition was determined in Shandong Province Cattle Corporation.

Fecal samples were collected from the rectum. The acid-insoluble ash method was used to determined dry matter (DM), crude protein (CP), neutral detergent fiber (NDF) and total energy (GE), and determine the gastrointestinal apparent digestibility.

In the last week of the trial, blood samples were collected from the jugular vein, and serum biochemical and hormonal markers were measured at Tai'an Central Hospital.

The rumen fluid was collected using the rumen fluid sampler in the last week of the test and the volatile fatty acid (VFA) content of the rumen fluid was measured by gas chromatography.

\subsection{Statistical Analysis}

The results were pretreated using Excel 2016 and then analyzed using SAS.8.2 software for linear model variance analysis and multiple comparisons. The data were considered significant different at $\mathrm{P}<0.05$, not significant at $\mathrm{P}>0.1$. A trend was considered when $0.05<\mathrm{P}<0.1$.

\section{Results and Analysis}

\subsection{Effects on Feed Intake and Apparent Digestibility}

The effects of diets on feed intake and apparent digestibility are shown in Table 3.

From the table, we can see that there were no significant differences in the dietary intake of different diets. The apparent digestibility of dry matter in the alfalfa group and wheat + alfalfa group was significantly higher than that in the wheat group $(\mathrm{P}<0.05)$. The apparent digestibility of crude protein, ADF and GE in alfalfa group was significantly higher than that in wheat group and wheat + alfalfa group $(\mathrm{P}<0.05)$, and the apparent digestibility of NDF in the alfalfa group was significantly higher than that in the wheat group, a trend of higher than that of the wheat + alfalfa group.

Table 3. Effects of different diets on feed intake and apparent digestibility.

\begin{tabular}{|c|c|c|c|c|c|}
\hline & \multicolumn{3}{|c|}{ Diet } & \multirow{2}{*}{ SEM } & \multirow{2}{*}{$\mathrm{P}$} \\
\hline & $\mathrm{X}$ & MX & M & & \\
\hline DMI $(\mathrm{kg} / \mathrm{d})$ & 20.70 & 20.73 & 20.93 & 0.22 & 0.9144 \\
\hline DM-Digestibility (\%) & $55.17^{\mathrm{b}}$ & $61.66^{\mathrm{a}}$ & $66.81^{\mathrm{a}}$ & 0.01 & 0.0003 \\
\hline CP-Digestibility (\%) & $60.43^{\mathrm{b}}$ & $63.30^{\mathrm{b}}$ & $70.55^{\mathrm{a}}$ & 1.12 & 0.0005 \\
\hline NDF-Digestibility (\%) & $56.19^{\mathrm{b}}$ & $60.58^{\mathrm{ab}}$ & $63.78^{\mathrm{a}}$ & 1.27 & 0.0488 \\
\hline ADF-Digestibility (\%) & $43.40^{\mathrm{b}}$ & $46.80^{\mathrm{b}}$ & $54.90^{\mathrm{a}}$ & 1.55 & 0.0072 \\
\hline GE-Digestibility (\%) & $55.01^{\mathrm{c}}$ & $61.45^{\mathrm{b}}$ & $67.24^{\mathrm{a}}$ & 1.27 & 0.0002 \\
\hline
\end{tabular}

Note: No significantly difference among values in the same line without a shoulder note or with the same letter $(\mathrm{P}>0.1)$. Values of significant difference were marked with different letters of shoulder note $(\mathrm{P}<$ 0.05). wheat group (group X), the wheat-alfalfa (group MX), alfalfa group (group M). 


\subsection{Effects of Different Diets on Rumen Metabolic Parameters}

The effects of diets on rumen fluid metabolic parameters in dairy cows are shown in Table 4.

The data show that there were no significant differences in rumen fluid acetic acid content in cows fed with different diets, indicating that different diets do not affect dairy cattle rumen acetic acid production. However, the wheat group produced a significantly higher content of propionic acid than group $\mathrm{M}$ and group MX. There was no significant difference between groups $M$ and MX in propionic acid content. The content of butyric acid in group MX was significantly higher than that in group $\mathrm{X}$, which was higher than that in group $\mathrm{M}$, while group $\mathrm{M}$ showed a trend higher than group $\mathrm{X}$ in butyric acid content. The difference of acetic/propionic ratio between group MX and group M was not significant, but these two groups were significantly higher than group $\mathrm{X}$ in acetic/propionic ratio. The $\mathrm{NH}_{3}-\mathrm{N}$ concentration in group $\mathrm{X}$ was significantly higher than that in groups $\mathrm{M}$ and MX. There was no significant difference in rumen $\mathrm{pH}$ among different diets.

\subsection{Effects of Different Diets on Serum Markers}

Table 5 shows the effects of different diets on serum biochemical indexes in Table 4. Effect of different diets on rumen metabolism of dairy cows.

\begin{tabular}{|c|c|c|c|c|c|}
\hline & \multicolumn{3}{|c|}{ diet } & \multirow{2}{*}{ SEM } & \multirow{2}{*}{$\mathrm{P}$} \\
\hline & $\mathrm{X}$ & $\mathrm{MX}$ & M & & \\
\hline Acetic $(\mathrm{mmol} / \mathrm{ml})$ & 74.11 & 73.35 & 71.12 & 1.63 & 0.7433 \\
\hline Propionic $(\mathrm{mmol} / \mathrm{ml})$ & $37.50^{\mathrm{a}}$ & $28.66^{\mathrm{b}}$ & $29.76^{\mathrm{b}}$ & 0.98 & 0.0001 \\
\hline Butyric $(\mathrm{mmol} / \mathrm{ml})$ & $11.46^{\mathrm{b}}$ & $13.98^{\mathrm{a}}$ & $12.64^{\mathrm{ab}}$ & 0.37 & 0.0171 \\
\hline Acetic/Propionic & $1.99^{\mathrm{b}}$ & $2.58^{\mathrm{a}}$ & $2.48^{\mathrm{a}}$ & 0.05 & $<0.0001$ \\
\hline $\mathrm{NH}_{3}-\mathrm{N}(\mathrm{mg} / \mathrm{L})$ & $117.89^{\mathrm{a}}$ & $86.94^{\mathrm{b}}$ & $94.22^{\mathrm{b}}$ & 3.11 & $<0.0001$ \\
\hline $\mathrm{pH}$ & 6.32 & 6.46 & 6.51 & 0.04 & 0.1658 \\
\hline
\end{tabular}

Note: No significantly difference among values in the same line without a shoulder note or with the same letter of shoulder note $(\mathrm{P}>0.1)$. Values of significant difference were marked with different letters of shoulder note $(\mathrm{P}<0.05)$. wheat group (group $\mathrm{X})$, the wheat-alfalfa (group MX), alfalfa group (group $\mathrm{M}$ ).

Table 5. Effect of different diets on serum biochemical indexes of dairy cows.

\begin{tabular}{|c|c|c|c|c|c|}
\hline & \multicolumn{3}{|c|}{ diet } & \multirow{2}{*}{ SEM } & \multirow{2}{*}{$\mathrm{P}$} \\
\hline & $\mathrm{X}$ & MX & M & & \\
\hline $\mathrm{TP}(\mathrm{g} / \mathrm{L})$ & $63.2^{\mathrm{b}}$ & $68.96^{\mathrm{a}}$ & $68.60^{\mathrm{a}}$ & 1.10 & 0.0532 \\
\hline Urea (mmol/L) & $5.35^{\mathrm{a}}$ & $5.68^{\mathrm{a}}$ & $4.59^{\mathrm{b}}$ & 0.13 & 0.0008 \\
\hline Glucose $(\mathrm{mmol} / \mathrm{L})$ & $1.59^{\mathrm{b}}$ & $1.67^{\mathrm{b}}$ & $2.76^{\mathrm{a}}$ & 0.10 & $<0.0001$ \\
\hline $\mathrm{HDL}(\mathrm{mmol} / \mathrm{L})$ & $2.37^{\mathrm{b}}$ & $2.95^{\mathrm{a}}$ & $2.71^{\mathrm{a}}$ & 0.07 & 0.0013 \\
\hline $\mathrm{LDL}(\mathrm{mmol} / \mathrm{L})$ & 0.35 & 0.38 & 0.35 & 0.01 & 0.4916 \\
\hline
\end{tabular}

Note: No significantly difference among values in the same line without a shoulder note or with the same letter of shoulder note $(\mathrm{P}>0.1)$. Values of significant difference were marked with different letters of shoulder note $(\mathrm{P}<0.05)$. wheat group (group X), the wheat-alfalfa (group MX), alfalfa group (group M). 
dairy cows.

The total serum protein content in group $\mathrm{M}$ and group MX was significantly higher than that in group $\mathrm{X}$. There were no significant differences between group $\mathrm{M}$ and group $\mathrm{MX}$ in total serum protein content. The urea contents in groups $\mathrm{X}$ and $\mathrm{MX}$ were significantly higher than that in group $\mathrm{M}$, and there were no significant differences between group $\mathrm{X}$ and group MX on urea content. There were no significant differences in glucose content between group $\mathrm{X}$ and group MX, but the two groups showed significantly lower glucose levels than group M. Group M and group MX had no differences in high density lipoprotein and cholesterol levels, and these levels were significantly higher than that in group X. There were no significant differences in uric acid and low density lipoprotein cholesterol among the three groups.

Table 6 shows the effect of different diets on serum hormone level in dairy cows. There were no significant differences in the levels of serum glucagon and insulin-like growth factor I among different groups. The insulin content in group $\mathrm{M}$ was significantly higher than that in groups $\mathrm{X}$ and MX. There were no significant differences between group $\mathrm{X}$ and group MX in insulin level. The levels of interleukin- 6 in group $M$ and group MX were significantly higher than that in group $\mathrm{X}$, and there were no significant differences between group $\mathrm{M}$ and group MX in interleukin-6 level.

\subsection{Effects of Different Diets on Milk Production and Body Condition in Dairy Cows}

Energy corrected milk yield was calculated as below:

Energy corrected milk yield $(\mathrm{kg} / \mathrm{d})$

$=(0.3246 \times$ milk yield $)+(12.86 \times$ milk fat yield $)+(7.04 \times$ milk protein yield $)$ [4] .

Table 7 shows the effects of different diets on milk production performance and body condition.

There were no significant differences in milk yield, the number of somatic cells in milk and body condition scores among the groups. Group $\mathrm{M}$ and group MX showed a significantly higher milk fat content than group $\mathrm{X}$. The lactose contents in groups $\mathrm{X}$ and MX were significantly higher than that of group M. Group X displayed a significantly higher content of urea nitrogen than the alfalfa

Table 6. Effects of different diets on serum hormone levels in dairy cows

\begin{tabular}{ccccccc}
\hline & \multicolumn{3}{c}{ Diet } & \multirow{2}{*}{ SEM } & P \\
\cline { 2 - 4 } & $\mathrm{X}$ & $\mathrm{MX}$ & $\mathrm{M}$ & & \\
\hline Glucagon $(\mathrm{pg} / \mathrm{ml})$ & 108.89 & 122.67 & 130.99 & 4.50 & 0.1284 \\
INS (uIU/ml) & $12.52^{\mathrm{b}}$ & $12.91^{\mathrm{b}}$ & $20.27^{\mathrm{a}}$ & 1.03 & 0.0012 \\
IGF-1 (ng/ml) & 12.14 & 14.35 & 17.94 & 1.56 & 0.3193 \\
IL-6 (pg/ml) & $255.10^{\mathrm{b}}$ & $358.22^{\mathrm{a}}$ & $339.49^{\mathrm{a}}$ & 17.58 & 0.0349 \\
\hline
\end{tabular}

Note: No significantly difference among values in the same line without a shoulder note or with the same letter $(\mathrm{P}>0.1)$. Values of significant difference were marked with different letters of shoulder note $(\mathrm{P}<$ 0.05). wheat group (group X), the wheat-alfalfa (group MX), alfalfa group (group M). 
group, and a trend of higher urea nitrogen than group MX. Group MX showed a trend of higher urea nitrogen than group M. Group $M$ and group MX were not significantly different in milk fat content, but were significantly higher in milk content than group X. Group MX had the highest milk protein content, followed by group $\mathrm{X}$. Group $\mathrm{X}$ showed the highest urea nitrogen content and group $\mathrm{M}$ the lowest.

\subsection{Effects of Different Diets on Economic Efficiency}

The dietary formula and prices are shown in Table 2. The effects of different diets on economic benefits are shown in Table 8 .

Group $\mathrm{M}$ diet had the highest cost, the lowest efficiency, followed by group MX diet. Group X diet had the lowest cost, the highest efficiency.

The cost of feed required to produce $1 \mathrm{~kg}$ of milk was calculated as the following:

$$
\text { Unit feed costs }=\text { feed costs/average milk production }
$$

Additional benefits were calculated based on the price 4 yuan $/ \mathrm{kg}$ for unprocessed milk. Compared with benefits from the alfalfa group, additional benefits were produced by each cow per day. (The source text of this paragraph needs be improved).

Table 7. Effects of different diets on milk performance and body condition

\begin{tabular}{ccccccc}
\hline & \multicolumn{3}{c}{ Diet } & & SEM & P \\
\cline { 2 - 5 } & X & MX & M & & \\
\hline Milk yield (kg/d) & 29.53 & 28.41 & 27.56 & 0.56 & 0.3553 \\
FCM 4\% (kg/d) & 24.58 & 25.19 & 24.22 & 0.52 & 0.7492 \\
ECM (kg/d) & 27.67 & 28.20 & 26.70 & & 0.57 & 0.5559 \\
Milk fat rate (\%) & $2.98^{\mathrm{b}}$ & $3.25^{\mathrm{a}}$ & $3.35^{\mathrm{a}}$ & & 0.04 & 0.0018 \\
Milk protein (\%) & $3.58^{\mathrm{ab}}$ & $3.60^{\mathrm{a}}$ & $3.52^{\mathrm{b}}$ & & 0.01 & 0.0763 \\
Lactose (\%) & $5.10^{\mathrm{a}}$ & $5.10^{\mathrm{a}}$ & $5.03^{\mathrm{b}}$ & 0.01 & 0.0038 \\
Cell number (10 thousand) & 23.72 & 15.46 & 26.38 & & 3.49 & 0.4147 \\
Urea nitrogen (mg/dL) & $15.48^{\mathrm{a}}$ & $15.06^{\mathrm{ab}}$ & $14.46^{\mathrm{b}}$ & 0.15 & 0.0282 \\
Body condition scoring (BCS) & 2.98 & 2.97 & 2.95 & 0.01 & 0.2763 \\
\hline
\end{tabular}

Note: No significantly difference among values in the same line without a shoulder note or with the same letter $(\mathrm{P}>0.1)$. Values of significant difference were marked with different letters of shoulder note $(\mathrm{P}<$ 0.05 ). wheat group (group $\mathrm{X}$ ), the wheat-alfalfa (group MX), alfalfa group (group $\mathrm{M}$ ).

Table 8. Effects of different diets on economic benefits

\begin{tabular}{cccc}
\hline & \multicolumn{3}{c}{ Diet } \\
\cline { 2 - 4 } & $\mathrm{X}$ & $\mathrm{MX}$ & $\mathrm{M}$ \\
\hline Feeding cost (yuan) & 56.26 & 58.81 & 62.12 \\
Unit feeding cost (yuan/kg) & 1.91 & 2.07 & 2.25 \\
Extra benefit (yuan) & 13.74 & 6.71 & - \\
\hline
\end{tabular}

Note: the feed cost was the cost for a cow per day. wheat group (group X), the wheat-alfalfa (group MX), alfalfa group (group M). 


\section{Discussion}

\subsection{Effects of Different Diets on Feed Intake and Apparent Digestibility}

The wheat group showed a generally lower apparent digestibility of the nutrient components than the alfalfa group, which was probably related to the higher starch content in the wheat hay diet. Studies have shown that increasing the ratio of starch to roughage will reduce the digestibility of NDF, but increasing the ratio of seed to roughage has no effect on digestibility [5]. Therefore, the more likely reason is that some of the wheat grains were not digested. The rich nutrients in the wheat grains can become more available by pre-processing the wheat hay to increase its digestibility. Whether grains are processed depends largely on the size of the animal, because grains are not easy to pass through the lower rumen opening of a small animal, but they are easy to pass the rumen opening in a large animal. As to cattle, whole grains could pass the rumen opening and discharge in the feces [6]. This will reduce the apparent digestibility of the diet. Ma and colleagues tested with soybean and other grains crushed to different sizes and found that the digestion by the stomach and small intestine can offset the digestion differences due to the size of soybean [7]. Yao showed that the whole grain seed coat has strong resistance to rumen microbes and digestive enzymes, but chewing and rumination can destroy mostly seed coats [8]. In this experiment, wheat grains were found in the feces of some of the cows in the group $\mathrm{X}$, and some dairy cows were able to completely digest the seeds, which is related to the difference in feeding and digestion behavior of different cows. Some dairy cows might have chewed and ruminated more fully, or could completely digest wheat grains in the stomach and small intestine.

\subsection{Effects of Different Diets on Metabolic Parameters of Rumen Fluid}

Carbohydrates in the diet are fermented by microorganisms in the rumen to produce short-chain volatile fatty acids (VFA, mainly acetic acid, propionic acid and butyric acid), and then absorbed into the blood by the rumen wall, which is the main way for ruminants to use energy.

The wheat hay contains wheat grains, so group M diet contains more potential concentrate components. In high-quality dietary conditions, rumen fermentation will produce mainly propionic acid, reduce the acetic/propionic ratio. A large number of easy-fermented carbohydrates will reduce the fermentation and degradation of fiber [9]. Group X diet contained more wheat grains, and the wheat grains contained a large amount of easily fermented wheat starch. Hererra measured the rumen degradation rate using the Nepalese bag method and found that the degradation rate (95\%) of starch was higher than that of corn starch (62\%) [10]. Group X diet contained more easy-fermentable carbohydrates than group $\mathrm{M}$ diet, could produce more propionic acid, and lower acetic/propionic ratio. Propionate is the main precursor of gluconeogenesis, which can provide 
most of the glucose required for in vivo metabolism in ruminants. Glucose plays an important role in the synthesis and production of milk lactose. Therefore, group $\mathrm{M}$ diet is more conducive to milk and lactose yield.

Most of the butyric acid produced in the rumen is converted to beta-hydroxybutyric acid during the absorption by the rumen wall, providing energy for body tissues, especially muscle. Fermentation by protozoa produces butyric acid which inhibits the use of propionic acid in the liver, acting positively on the milk fat content and negatively on lactose content. It is worth mentioning that studies have shown that acetic acid and butyric acid can be converted to each other, and conversion of acetic acid to butyric acid has net ATP production, which is beneficial for microbial metabolism [11] [12] [13]. The results of this study show that the yield of butyric acid in group MX is higher, indicating that the wheat hay and alfalfa mixed diets are more favorable for the production of butyric acid, If the butyric acid can be converted into acetic acid, it is conducive to synthesis of more milk fat.

$\mathrm{NH}_{3}-\mathrm{N}$ in the rumen is a final product of dietary crude protein degradation and is the nitrogen source for the synthesis of rumen microbes. In this study, the concentration of $\mathrm{NH}_{3}-\mathrm{N}$ in group $\mathrm{X}$ was high, which indicates that the rate of $\mathrm{NH}_{3}-\mathrm{N}$ produced by the rumen microbial degradation was greater than the needs of microbial synthesis in Group X. This could have increased the nitrogen loss during rumen nitrogen cycling and reduces the efficiency of $\mathrm{N}$ utilization. This is because group X diet contained a higher level of soybean meal than the diets of the other two groups. Soybean meal had a high rate of degradation and contains more biodegradable proteins, which could increase the $\mathrm{NH}_{3}-\mathrm{N}$ concentration and provide more nitrogen for the synthesis of bacterial protein. $\mathrm{NH}_{3}$ that had not been used by microorganisms, could have entered the blood through the rumen wall and was used for urea synthesis in the liver, thus entered the rumen nitrogen cycle.

Rumen $\mathrm{pH}$ is an important indicator of rumen environment. Normal fermentation requires a normal range of rumen $\mathrm{pH}$. In this experiment, the rumen $\mathrm{pH}$ values of different diets were not significantly different and were within the normal range $(5.5$ - 7.5). Group X diet contained more readily available carbohydrates such as wheat starch, which were more likely to produce large amounts of acid, but wheat hay has a higher NDF level than alfalfa, which could neutralize excess acid by stimulating dairy cows to produce more $\mathrm{NH}_{3}$, which could also neutralize excess acid, maintaining the normal rumen $\mathrm{pH}$. The results of this study show that different diets ( $\mathrm{M}, \mathrm{MX}$ and $\mathrm{X}$ ) did not affect rumen $\mathrm{pH}$, and the use of whole plant wheat did not cause rumen acidosis.

\subsection{Effects of Different Diets on Serum Biochemical Indexes of Dairy Cows}

Serum biochemical and hormone indicators reflect comprehensively the digestion and metabolism of nutrients, the balance of the environment and health 
status in animals. Serum total protein can reflect the level of dietary protein and digestion and absorption of protein. The urea content in the blood can reflect the nitrogen intake and absorption [14]. Xu showed that high protein diets could increase serum protein and urea levels [15]. This is inconsistent with the results of this test (diets and other crude protein). The inconsistency may be related to the difference in dietary $\mathrm{CP}$ among different groups. Group $\mathrm{X}$ diet has more $\mathrm{CP}$ from soybean meal. In the rumen, $\mathrm{CP}$ is degraded faster, cannot be used fully by microbes. There could be a considerable portion of $\mathrm{CP}$ entering into the small intestine in the form of amino acids, or in the form of $\mathrm{NH}_{3}$ through the rumen wall into the blood, forming urea in the liver. This could increase the serum urea content. This could also reduce the efficiency of nitrogen use.

Lipids in the blood are mainly transported in the form of lipoproteins [16]. Group M and Group MX had higher levels of high density lipoprotein (HDL), indicating that alfalfa hay has more advantages in the digestion and absorption of lipids. This could be conducive to the synthesis of milk fat. The serum total protein, urea and HDL levels in Group MX were high. This suggests that alfalfa + wheat diet was high in lipid digestion and metabolism, but also increased the possibility of milk fat and milk protein production.

Group X had a higher propionic acid production. Propionic acid can produce glucose by gluconeogenesis, and theoretically group X could have a higher serum glucose content. Many studies have confirmed this. However, in this study, group $M$ had the highest serum glucose content. This may be due to the feed being freely accessible to cows in this test. In the process of animal feeding, gluconeogenesis reaches the peak, while fasting greatly reduces gluconeogenesis [17]. When collecting blood, the free feeding of dairy cows could have caused a difference in blood glucose concentration.

Group $M$ had the highest glucose concentration and the highest insulin content. Insulin can lower blood sugar, inhibit gluconeogenesis and glycogen breakdown [18]. This also supports the notion that the high level of glucose in group $M$ is due to an increase in gluconeogenesis during ingestion.

Interleukin-6 participates in the inflammatory response. It is an important immune indicator. The serum level of interleukin- 6 in group $\mathrm{X}$ was the lowest, indicating that wheat may have anti-inflammatory effect. Chang reported that wheat germ can be used to prepare anti-tumor, anti-oxidation, anti-fungal and anti-inflammatory and other functional components by microbial fermentation [19]. Many studies at home and abroad also support this point [20] [21]. The medicinal value of wheat on ruminants remains to be studied.

\subsection{Effects of Different Diets on Milk Production and Body Condition}

The wheat hay diet had no significant effects on the milk production in dairy cows. Group $\mathrm{M}$ had the highest milk yield, followed by group MX, and group $\mathrm{M}$ had the least. It seems that wheat hay can increase milk production in dairy 
cows, but did not reach statistical significance. The results were similar when milk production was measured with fat corrected and energy corrected milk. Although group $\mathrm{X}$ was lower than group $\mathrm{M}$ in digestibility, but not in the milk yield, which shows that digestible nutrients in group $\mathrm{X}$ diet were used better, which make up inferior digestibility of group $\mathrm{X}$ diet.

Milk fat is an important indicator for the quality of milk. Group $\mathrm{M}$ and group MX were not significantly different in milk fat, but displayed significantly higher milk fat contents than group $\mathrm{X}$, which shows that a complete replacement of alfalfa by wheat hay reduces milk fat content, but alfalfa + wheat diet does not reduce the milk fat content. A large number of tests have shown that a high concentrate level promotes propionic acid fermentation, is not conducive to acetic acid fermentation, reduces the synthesis of milk fat. This can explain the results of our test, where group X contained more wheat grains and soybean meal, which potentially increased the concentrate to roughage ratio, leading to more ruminal propionic acid fermentation (relative to acetic acid and butyric acid). Studies by Guo have shown that rumen fermentation of acetic acid, butyric acid and long chain fatty acids could improve milk fat content [22]. This is consistent with the results of our trial, where rumen fluid butyric acid and serum high density lipoprotein cholesterol (HDL) levels were high in groups M and MX. However, there were no differences in rumen acetic acid production among the groups, although there were differences in milk fat content. This finding was inconsistent to the theory by Van Soest, Emery, which suggests that acetic acid is the precursor of milk fat, but it is consistent with the findings by Baum and Davis [23] [24] [25] [26]. Bauman measured the actual yield of volatile fatty acids in the rumen using radioisotope technology and found that reduction in milk fat caused by dietary changes could lead to less propionic acid, without much change in acetic acid production, resulting in acetic/propionic ratio [25]. This indicates that even if acetic acid production is sufficient, the milk fat production could decline. In other words, the ratio of acetic/propionic has a greater impact on milk fat content. Davis reported that when the proportion of propionic acid in rumen VFA exceeded the threshold $25 \mathrm{~mol} / 100 \mathrm{~mol}$ or the ratio of acetic acid to propionic acid is less than 2.2 [26], the milk fat percentage was greatly reduced, and these threshold levels may occur with different tests [27], which is consistent with the low acetic/propionic ratio and low milk fat in group X.

Milk is a complete protein source with the highest nutritional value. Milk protein comes mainly from protein synthesis in the mammary gland and proteins in the blood of dairy cows. In this study, although group $M$ had the highest total serum protein content, but this group had the lowest milk protein content. Group MX had the highest milk protein content, followed by Group X. This is mainly because more than $90 \%$ of milk protein was synthesized in the mammary gland from amino acids [16]. Many studies have shown that dietary CP levels affect milk protein production [28]. In this study, CP level was the same for all diets. Although Group X diet contained more soybean meal and other readily 
degradable proteins, group MX produced the highest level of milk protein content, probably because alfalfa + wheat diet contained more feed ingredients and more balanced amino acid composition, which contributed to the synthesis of more proteins in the breast, which also confirms the theory that dietary amino acid balance has a greater impact on milk protein synthesis. Group X diet has a high protein degradation rate, which leads to discordance in rumen nitrogen release and energy production. Excessive nitrogen will enter the rumen nitrogen cycle (NRC, 2001), which is also the reason for the high levels of serum and milk urea nitrogen content in group $\mathrm{X}$.

Milk osmolality is mainly maintained by lactose. The lactose content had little change in this trial. Glucose for lactose synthesis in ruminants comes mainly from gluconeogenesis using propionic acid and starch from absorption in the small intestine. In this experiment, group $\mathrm{X}$ had the highest dietary starch, and the highest content of propionic acid. Propionic acid is the precursor of gluconeogenesis, so it could provide more glucose for the synthesis of lactose. However, in this study, the serum glucose content in group $\mathrm{X}$ was low, which may be related to the test conditions. In this trial, the cows were not fasted during the blood collection period, and the gluconeogenesis reached the peak at the time of eating [17], which greatly increased the uncertainty of blood glucose levels.

\subsection{Economic Efficiency}

The factors that determine the economic benefits of dairy farms are the price of raw milk, the cost of production and the milk production. The cost of feed constitutes the largest proportion.

The economic analysis revealed the benefits of different diets. The imported alfalfa diet had the highest feed cost, being 62.12 yuan per cow per day. About $50 \%$ replacement of the alfalfa could reduce the feed cost to 58.81 yuan per cow per day, saving 3.31 yuan per day. When all dietary alfalfa was replaced by wheat hay, each cow saved 5.86 yuan per day in feed costs. Considering milk production, the use of alfalfa diet had the highest feed cost for the production of $1 \mathrm{~kg}$ of milk, 2.25 yuan. The use of wheat and alfalfa-wheat group of diets, respectively, reduced the cost to 1.91 yuan and 2.07 yuan for $1 \mathrm{~kg}$ of milk, saving 0.36 yuan and 0.18 yuan per $\mathrm{kg}$. When the price of the unprocessed milk was 4 yuan $/ \mathrm{kg}$, each cow could produce 13.74 yuan and 6.71 yuan more benefits per day, respectively, using the wheat and alfalfa-wheat diets, compared with the alfalfa diet.

Therefore, under the current test conditions, the use of wheat hay instead of imported alfalfa in dairy cows can improve the production efficiency of dairy farms, mainly from the reduction of feed costs.

\section{Conclusion}

Dairy production performance is stable if alfalfa is partially or completely replaced with wheat hay. Wheat diet is safe and feasible. It reduces significantly 
feeding costs and increases economic benefits.

\section{Acknowledgements}

The study was financially supported by the earmarked fund for Modern Agro-industry Technology Research System of China (CARS-37), Cattle Agro-industry Technology Research System of Shandong Province (SDAIT-12-011-06), Natural Science Fund of China (31572427) (31372340), National Key R \& D Program of China, SYL2017YSTD08 and Major Application Technology Innovation Project of Shandong Province. The author gratefully thanks the staff of Shandong Gaosu Dairy Farm.

\section{Conflicts of Interest}

All authors report no conflict of interest in regard to this study.

\section{References}

[1] Li, S.L., Chen, P. and Zheng, B.W. (2006) How to Improve Milk Yield and Quality by Improving the Efficiency of Feed Conversion in Dairy Cows. National Symposium on Feed Nutrition.

[2] Adamson, A.H. and Reeve, A. (1992) Nutritional Evaluation of Whole-Crop Wheat. Chalcombe Publication, Aberystwyth, 85-96.

[3] Beck, P.A., Stewart, C.B. and Gray, H.C. (2009) Effect of Wheat Forage Maturity and Preservation Method on Forage Chemical Composition and Performance of Growing Calves Fed Mixed Diets. Journal of Animal Science, 87, 4133-4142. https://doi.org/10.2527/jas.2009-2184

[4] Bu, D.P., Wang, J.Q. and Dhiman, T.R. (2007) Effectiveness of Oils Rich in Linoleic and Linolenic Acids to Enhance Conjugated Linoleic Acid in Milk from Dairy Cows. Journal of Dairy Science, 90, 998-1007. https://doi.org/10.3168/jds.S0022-0302(07)71585-0

[5] Bines, J.A. and Brown, R.E. (1968) Incorporation of Carbon from Acetate and Butyrate into Milk Components. Journal of Animal Science, 51, 698-705. https://doi.org/10.3168/jds.S0022-0302(68)87058-4

[6] Yao, J.H. (1991) Research and Application of Rumen-Feeding Method and Coarse or Non-Crushed Seeds. Feed Expo, 18-20.

[7] Ma, W.J., Sun, W. and Song, E.L. (2009) Effects of Soybean Crushing Grain Size on Meat Production Performance of Hybrid Cattle. Feed Research, 5, 58-59.

[8] Yao, J.H. and Xue, Q. (1994) Effects of Cattle and Sheep Feeding Whole Grains on Digestion and Utilization Performance. Inner Mongolia Animal Husbandry, 25-28.

[9] Bergman, E.N. (1990) Energy Contributions of Volatile Fatty Acids from the Gastrointestinal Tract in Various Species. Physiological Reviews, 70, 567-590. https://doi.org/10.1152/physrev.1990.70.2.567

[10] Herrera-Saldana, R.E., Huber, J.T. and Poore, M.H. (1990) Dry Matter, Crude Protein, and Starch Degra Dability of Five Cereal Grains 1. Journal of Dairy Science, 73, 2386-2393. https://doi.org/10.3168/jds.S0022-0302(90)78922-9

[11] Gray, F.V., Pilgrim, A.F. and Rodda, H.J. (1952) Fermentation in the Rumen of the Sheep. 4. The Nature and Origin of the Volatile Fatty Acids in the Rumen of the Sheep. Journal of Experimental Biology, 29, 57-65. 
[12] Gray, W.R. (1967) Dansyl Chloride Procedure. Methods in Enzymology, 11, 139-151. https://doi.org/10.1016/S0076-6879(67)11014-8

[13] Leng, R.A. (1965) Ketone-Body Metabolism in Normal and Underfed Pregnant Sheep in Pregnancy Toxaemia. Research in Veterinary Science, 6, 433-441.

[14] Yang, H.B. and Liu, H. (2015) Effects of Dietary Concentrate-to-Forage Ratio on Performance in Ruminant. China Dairy Cattle, 5, 11-14.

[15] Xu, X.T., Wang, B.L. and Cheng, G.M. (2016) Effects of Dietary Concentrate-toForage Ratio on Performance, Serum Biochemical Indices and Economic Benefit in Dubo Sheep. Chinese Animal Husbandry and Veterinary Medicine.

[16] Yang, F. (2011) Animal Nutrition. China Agriculture Press, Beijing.

[17] Lu, D.X. (2010) Theory and Application of Glucose Nutrition Regulation in Ruminant. Journal of Animal Science and Animal Husbandry, No. 6, 402-409.

[18] Chen, J. (2003) Poultry Physiology. China Agricultural Press, Beijing.

[19] Chang, X.H., Chen, G.P. and Zhang, J.Y. (2014) Advances in Biotransformation of Wheat Germ. Cereal and Food Industry, 21, 6-11.

[20] Hidvegi, M. and Resetar, A. (2005) Use of Fermented Wheat-Germ in the Feeding and Veterinary Practice. US, US 20050249838 A1.

[21] Zhao, X.L., Xu, G.F. and Wu, B. (2003) Effects of Crude Extracts of Wheat Germ Flavonoids on the Mechanism of Breast Cancer. Chinese Journal of Public Health, 19, 169-171.

[22] Guo, D.S. and Peng, X.L. (2011) Effects of Different Coarse and Mixed Diets on Milk Performance and Milk Quality of Dairy Cows. Journal of Southwest China Agricultural University, 24, 297-300.

[23] Soest, P.J.V. (1994) Nutritional Ecology of the Ruminant. Cornell University Press, Ithaca, 44, 2552-2561.

[24] Emery, R.S. and Brown, L.D. (1961) Effect of Feeding Sodium and Potassium Bicarbonate on Milk Fat, Rumen $\mathrm{pH}$, and Volatile Fatty Acid Production 1. Journal of Dairy Science, 44, 1899-1902. https://doi.org/10.3168/jds.S0022-0302(61)89981-5

[25] Bauman, D.E., Davis, C.L. and Bucholtz, H.F. (1971) Propionate Production in the Rumen of Cows Fed either a Control or High-Grain, Low-Fiber Diet. Journal of Dairy Science, 54, 1282-1287. https://doi.org/10.3168/jds.S0022-0302(71)86021-6

[26] Davis, C.L. (1978) The Use of Buffers in the Rations of Lactating Dairy Cows [Milk Fat Percent]. Regulation of Acid Base Balance.

[27] Woodford, S.T. and Murphy, M.R. (1988) Effect of Forage Physical Form on Chewing Activity, Dry Matter Intake, and Rumen Function of Dairy Cows in Early Lactation. Journal of Dairy Science, 71, 674-686.

https://doi.org/10.3168/jds.S0022-0302(88)79606-X

[28] Broderick, G.A. (2003) Effects of Varying Dietary Protein and Energy Levels on the Production of Lactating Dairy Cows. Journal of Dairy Science, 86, 1370-1381. https://doi.org/10.3168/jds.S0022-0302(03)73721-7 